\title{
CONSIDERAÇÕES SOBRE A ELETROGERAÇÃO DE PERÓXIDO DE HIDROGÊNIO
}

\author{
Christiane A. R. Ragnini, Rosana A. Di Iglia e Rodnei Bertazzoli*
}

Departamento de Engenharia de Materiais, FEM/UNICAMP, CP 6122, 13083-970 Campinas - SP

Recebido em 22/7/99; aceito em 16/11/00

\begin{abstract}
CONSIDERATIONS ON THE HYDROGEN PEROXIDE ELECTROGENERATION. This paper presents some results that may be used as previous considerations to a hydrogen peroxide electrogeneration process design. A kinetic study of oxygen dissolution in aqueous solution is carried out and rate constants for oxygen dissolution are calculated. Voltammetric experiments on vitreous carbon cathode shown that the low saturation concentration drives the oxygen reduction process to a mass transfer controlled process which exhibits low values of limiting currents. Results have shown that the hydrogen peroxide formation and its decomposition to water are separated by $400 \mathrm{mV}$ on the vitreous carbon surface. Diffusion coefficients for oxygen and hydrogen peroxide are calculated using data taken from Levich and Tafel plots. In a series of bulk electrolysis experiments hydrogen peroxide was electrogenerated at several potential values, and concentration profiles as a function of the electrical charged passed were obtained. Data shown that, since limiting current plateaus are poorly defined onto reticulated vitreous carbon, cathodic efficiency may be a good criterion for choosing the potential value in which hydrogen peroxide electrogeneration should be carried out.
\end{abstract}

Keywords: hydrogen peroxide; electrosynthesis of hydrogen peroxide; oxygen reduction; vitreous carbon; kinetics of oxygen dissolution.

\section{INTRODUÇÃ̃O}

Quando a questão da preservação ambiental é levada em consideração, o peróxido de hidrogênio apresenta-se como um reagente único, visto que seu produto de decomposição é a água. Como oxidante, sua aplicação abrange a oxidação seletiva e manufatura de compostos orgânicos, branqueamento de polpa na indústria de papel e, no tratamento de efluentes aquosos, é responsável pela mineralização de vários compostos orgânicos ${ }^{1-3}$. O uso do peróxido de hidrogênio é bastante difundido e a previsão de crescimento do mercado consumidor mundial é de $10 \%$ ao ano ${ }^{4}$. Neste contexto, a importância do peróxido de hidrogênio eletrogerado cresce à medida que este processo elimina os riscos e custos de armazenamento e transporte. A eletrogeração deste oxidante pode ser considerada de dois tipos: in loco, onde um reator eletrolítico produz e concentra para uso descontínuo, ou in situ, onde uma solução contendo um composto orgânico a ser oxidado percola continuamente um reator, no qual o peróxido de hidrogênio é simultaneamente eletrogerado. Como exemplo do processo in situ, a literatura tem demonstrado a viabilidade do uso do peróxido de hidrogênio eletrogerado para tratamento de efluentes aquosos industriais, através da destruição de fenol, formaldeído, anilinas, cloroanilinas, ácidos orgânicos, corantes, e reduzindo altos valores de DQO para concentrações menores que $5 \mathrm{ppm}^{5-13}$. Por outro lado, a indústria de papel e celulose pode ser uma das maiores beneficiárias da eletrogeração in loco. O branqueamento do papel e da polpa é feito com peróxido de hidrogênio em meio alcalino e a eletrogeração e acumulação para este fim tem sido objeto de alguns estudos ${ }^{14,15}$. Até o presente momento, a eletrogeração de peróxido de hidrogênio para a indústria de creme dental permanece uma área inexplorada.

A eletrólise tem uma extensa história de participação na fabricação do peróxido de hidrogênio. Por muitos anos, o peróxido de hidrogênio foi fabricado por eletrólise através da formação de persulfato no anodo que, a seguir, era hidrolisado. Ainda hoje, quase todo o peróxido de hidrogênio é fabricado através da redução do oxigênio pelo hidrogênio, usando a antraquinona como catalisador ${ }^{16}$. Este processo exige uma alta disponibilidade de hidrogênio e o uso em larga escala de um solvente não-aquoso para permitir a reciclagem do catalisador.

Neste sentido, a tecnologia eletroquímica pode oferecer um meio eficiente para a eletrossíntese do peróxido de hidrogênio e para o tratamento eletrolítico de efluentes. Nos últimos 20 anos a engenharia eletroquímica lançou mão dos conceitos já sedimentados de eletroquímica e transportou-os da bancada do laboratório para a produção industrial, demonstrando uma grande versatilidade. Hoje em dia, é possível encontrar na literatura uma enorme variedade de projetos de reatores eletrolíticos, alguns em fase de comercialização, capazes de executar vários processos anódicos ou catódicos, utilizando vários tipos de materiais para eletrodos e membranas ${ }^{17}$.

Em processos eletrolíticos, o peróxido de hidrogênio pode ser produzido através de uma reação catódica empregando-se o oxigênio como principal reagente. A redução do oxigênio, em meio aquoso, pode ser representada pelas equações a seguir:

$\mathrm{O}_{2}+\mathrm{H}_{2} \mathrm{O}+2 \mathrm{e}^{-} \rightarrow \mathrm{HO}_{2}^{-}+\mathrm{OH}^{-}$ou

$\mathrm{O}_{2}+2 \mathrm{H}^{+}+2 \mathrm{e}^{-} \rightarrow \mathrm{H}_{2} \mathrm{O}_{2}$

que representam as etapas de interesse no processo de produção do peróxido de hidrogênio. No entanto, o eletrodo de oxigênio constitui um sistema complexo, onde a reação global envolve a transferência de quatro elétrons e o produto final é a água, ou:

$\mathrm{O}_{2}+2 \mathrm{H}^{+}+2 \mathrm{e}^{-} \rightarrow \mathrm{H}_{2} \mathrm{O}_{2}+2 \mathrm{H}^{+}+2 \mathrm{e}^{-} \rightarrow \mathrm{H}_{2} \mathrm{O}$

Sobre algumas superfícies, como na de mercúrio, os dois processos podem estar separados por até $1,0 \mathrm{~V}$, tornando viável a produção do oxidante ${ }^{18}$. Pelo menos quatorze rotas diferentes podem ser encontradas na literatura, que também considera várias possibilidades de etapas determinantes da velocidade da reação ${ }^{18}$.

No entanto, a baixa solubilidade do oxigênio em soluções aquosas é um fator limitante fazendo com que a reação de redução seja controlada por difusão com baixos valores de 
corrente limite. Porém, esta dificuldade, pode ser contornada usando eletrodos tridimensionais que possuem altas áreas disponíveis para a reação e permitem velocidades mais altas de transferência de massa ${ }^{7-15}$.

Este trabalho apresenta um estudo cinético da dissolução de oxigênio em alguns eletrólitos que poderão ser empregados na eletrogeração de peróxido de hidrogênio. Além disso, o estudo voltamétrico realizado evidenciou o processo de redução do oxigênio em duas etapas sobre a superfície do carbono vítreo. Na sequiência, utilizou-se um eletrodo tridimensional de carbono vítreo reticulado para a eletrogeração e acumulação de peróxido de hidrogênio. Os resultados obtidos apresentam informações importantes para o projeto de células eletrolíticas com catodo tridimensional para a produção de peróxido de hidrogênio.

\section{DETALHES EXPERIMENTAIS}

$\mathrm{O}$ estudo da cinética de dissolução de $\mathrm{O}_{2}$ nas soluções usadas como eletrólito foram feitos através do borbulhamento direto do gás e a concentração na fase aquosa foi monitorada através de um eletrodo sensor de oxigênio dissolvido (OD). Estes testes permitiram a determinação da concentração de saturação do oxigênio no meio, que foi utilizada nos experimentos posteriores. Foram usadas duas soluções com $0,5 \mathrm{M}$ de $\mathrm{Na}_{2} \mathrm{SO}_{4}$, com $\mathrm{pH}$ de 8 e 10, e uma solução $1 \mathrm{M}$ de $\mathrm{NaOH}, \mathrm{pH} 14$.

A seguir, a reação de redução do oxigênio foi estudada sobre a superfície de um eletrodo de disco rotatório de carbono vítreo $\left(\right.$ área $=0,12 \mathrm{~cm}^{2}$ ) para a determinação dos potenciais onde ocorrem os eventos catódicos representados pelas equações (1) e (2). Estes experimentos foram comandados por um potenciostato Autolab PGSTAT 20. Na célula eletrolítica, de fundo hemisférico, foram acomodados, além do eletrodo de trabalho, o contra eletrodo de platina e um referência de calomelano em $\mathrm{KCl}$ saturado.

O mesmo estudo foi repetido sobre o carbono vítreo reticulado (CVR). Para tal, foi construído um eletrodo de CVR, que foi colado à superfície do eletrodo de disco rotatório de carbono vítreo monolítico. A porosidade do CVR utilizado foi de $45 \mathrm{ppi}$ (poros por polegada linear) com área de $27 \mathrm{~cm}^{2} \mathrm{~cm}^{-3}$. As dimensões do cilindro foram tais que a área obtida para reação foi de $20( \pm 0,2) \mathrm{cm}^{2}$. Nesta fase reproduziu-se o mesmo arranjo experimental anterior trocando apenas o eletrodo de referência. Para evitar problemas com queda ôhmica utilizou-se um sistema de semi-referência de Ag/AgI, imerso no próprio eletrólito. A vantagem deste eletrodo é representada pelas suas pequenas dimensões (fio de $\mathrm{Ag}$ com $0,3 \mathrm{~mm}$ de espessura), permitindo o seu posicionamento tão próximo quanto necessário da superfície do eletrodo de trabalho, sem interferir nas condições hidrodinâmicas do experimento durante o uso do eletrodo rotatório. $\mathrm{O}$ potencial deste eletrodo em relação ao calomelano em $\mathrm{KCl}$ saturado é de $620 \mathrm{mV}$.

A seguir, utilizou-se um eletrodo de CVR de $20 \mathrm{ppi}$, conforme pode ser observado na Figura 1. Este eletrodo foi construído na forma de um cilindro oco, com dimensões de $5,0 \mathrm{~cm}$ de comprimento, $3,7 \mathrm{~cm}$ de diâmetro externo e $2,0 \mathrm{~cm}$ de diâmetro interno. Com este eletrodo foram feitos experimentos a potencial constante para monitorar a concentração de peróxido de hidrogênio eletrogerado em função do tempo de polarização. A concentração do peróxido foi determinada através da titulação com permanganato de potássio.

\section{RESULTADOS E DISCUSSÃO}

\section{Cinética da Dissolução de Oxigênio em Soluções Aquosas}

Conforme exposto, a eletrogeração do peróxido de hidrogênio ocorre a partir da redução do oxigênio dissolvido no meio eletrolítico. Neste caso, é importante que o eletrólito trabalhe na concentração de saturação, e que o oxigênio

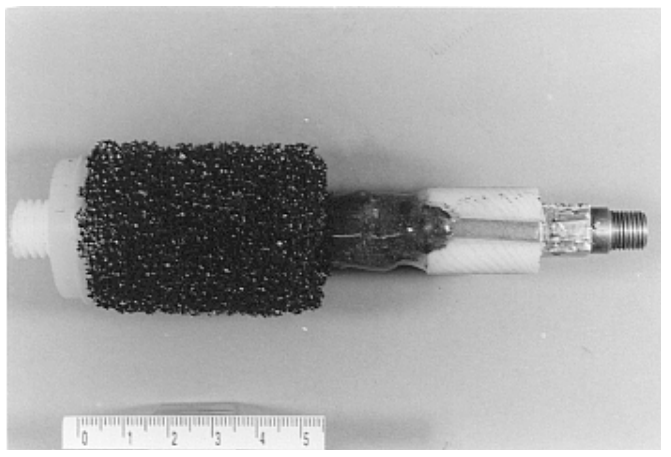

Figura 1. Eletrodo cilíndrico de CVR de 20 ppi usado para a eletrogeração de peróxido de hidrogênio.

reduzido possa ser prontamente reposto na solução. Neste estudo, foram determinadas as constantes de velocidade de dissolução do oxigênio em vários meios que poderão posteriormente ser utilizados como eletrólito para a produção de peróxido de hidrogênio.

Para tanto foram utilizadas as soluções acima descritas. Borbulhou-se oxigênio nestas soluções através de um dispersor sinterizado fino e a variação da concentração de oxigênio dissolvido foi monitorada ao longo do tempo através de um sensor de OD.

A Figura 2 mostra os perfis de concentração de oxigênio ao longo do tempo de borbulhamento para as soluções identificadas no gráfico. Partindo-se de um valor inicial, a concentração de oxigênio aumenta exponencialmente até atingir a saturação. A concentração de saturação foi de 25,14 \pm $0,04 \mathrm{mg} \mathrm{L}^{-1}$, independente da composição da solução, e na temperatura de $23{ }^{\circ} \mathrm{C}$. O tempo necessário para a saturação de $0,5 \mathrm{~L}$ de solução foi de 20 minutos.

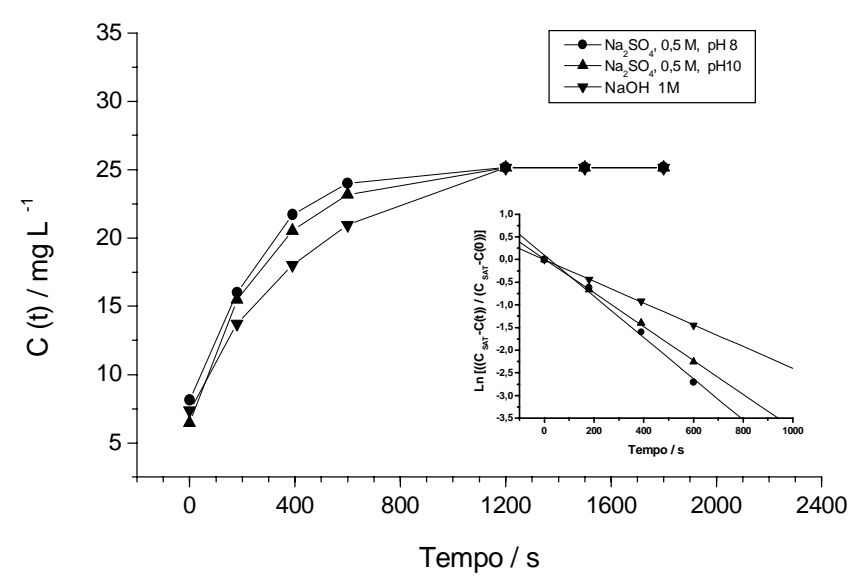

Figura 2. Perfil de concentração de oxigênio nas soluções descritas em função do tempo de borbulhamento. Detalhe. Linearização das curvas de concentração para determinação das constantes de velocidade de dissolução.

Para determinar o coeficiente de transporte de massa para a fase líquida $\left(\mathrm{k}_{\mathrm{L}}\right)$ durante o borbulhamento foi necessário considerar a concentração de saturação $\left(\mathrm{C}_{\mathrm{SAT}}\right)$, e a variação da concentração de $\mathrm{O}_{2}$ dissolvido $\left(\mathrm{dC}_{\mathrm{L}} / \mathrm{dt}\right)$ pode ser expressa de acordo com o seguinte balanço de massa:

$\frac{\mathrm{dC}_{\mathrm{L}}(\mathrm{t})}{\mathrm{dt}}=\mathrm{k}_{\mathrm{L}}\left(\mathrm{C}_{\mathrm{SAT}}-\mathrm{C}_{\mathrm{L}}(\mathrm{t})\right)$

Integrando-se entre limites apropriados obtém-se a solução: 
$\mathrm{C}_{\mathrm{L}}(\mathrm{t})=\mathrm{C}_{\mathrm{SAT}}-\left(\mathrm{C}_{\mathrm{SAT}}-\mathrm{C}_{0}\right) \exp \left(-\mathrm{k}_{\mathrm{L}} \mathrm{t}\right)$

onde $\mathrm{C}_{0}$ é o valor de $\mathrm{C}_{\mathrm{L}}(\mathrm{t})$ em $\mathrm{t}=0$.

A linearização da equação (5) fornece o valor da constante de velocidade da dissolução de oxigênio, ou o coeficiente de transporte de massa para a solução. O detalhe da Figura 2 mostra esta linearização onde os valores de $\mathrm{k}_{\mathrm{L}}$ são representados pelos coeficientes angulares das retas. A Tabela 1 compara estes valores para cada solução, bem como as velocidades de dissolução numa solução não saturada.

Como pode ser observado na Tabela 1 , o processo de redução de oxigênio deve levar em consideração os baixos valores de $\mathrm{k}_{\mathrm{L}} \mathrm{e}$, em consequência, a baixa velocidade de dissolução do gás na fase líquida. Sendo assim, é necessário estabelecer um compromisso entre a quantidade de oxigênio consumido no catodo e aquela que pode ser reposta na solução mediante o borbulhamento permanente de oxigênio, de forma a não comprometer o rendimento elétrico da eletrogeração de peróxido de hidrogênio.

Tabela 1. Constante de velocidade de transferência de massa para a fase líquida e velocidade de dissolução do oxigênio durante o borbulhamento.

\begin{tabular}{lcc}
\hline Solução & $\mathrm{k}_{\mathrm{L}} / \mathrm{s}^{-1}$ & $\begin{array}{c}\text { Veloc. Dissolução/ } \\
\mu \text { mol L } \text { L }^{-1}\end{array}$ \\
\hline $\mathrm{Na}_{2} \mathrm{SO}_{4}-0,5 \mathrm{M}-\mathrm{pH} 8$ & 0,0046 & 0,144 \\
$\mathrm{Na}_{2} \mathrm{SO}_{4}-0,5 \mathrm{M}-\mathrm{pH} \mathrm{10} 10$ & 0,0037 & 0,116 \\
$\mathrm{NaOH} \mathrm{1M-pH} \mathrm{14}$ & 0,0024 & 0,075 \\
\hline
\end{tabular}

Se, durante o processo eletrolítico, for possível manter a concentração no valor de saturação (vide Figura 2) a corrente limite ainda será muito baixa. Considerando a concentração de saturação de $25 \mathrm{mg} \mathrm{L}^{-1}$ e, estimando a espessura da camada de difusão $(\delta)$ entre $10^{-2}$ e $10^{-3} \mathrm{~cm}$ e o coeficiente de difusão (D) do $\mathrm{O}_{2}$, de forma benevolente, como $10^{-5} \mathrm{~cm}^{2} \mathrm{~s}^{-1}$, é possível estimar a corrente limite a partir da equação:

$\mathrm{i}_{\mathrm{L}}=\mathrm{nF} \frac{\mathrm{D}}{\delta} \mathrm{C}_{\mathrm{SAT}}$

onde n e F são o número de elétrons trocados por mol de $\mathrm{HO}_{2}{ }^{-}$ produzido (2, neste caso) e a constante de Faraday, respectivamente. Utilizando a equação (6), a corrente limite ficará entre 0,15 e $1,5 \mathrm{~mA} \mathrm{~cm}^{-2}$. Valores de densidade de corrente tão baixos dificultam o projeto de uma célula eletrolítica e a viabilização de um possível processo industrial, a menos que sejam utilizados eletrodos tridimensionais com alta relação área de reação/volume do catodo.

\section{Estudo da Redução do Oxigênio sobre Carbono Vítreo Monolítico}

Com o objetivo de saber se o carbono vítreo é um substrato adequado para a redução do oxigênio, e qual a seletividade deste material em privilegiar a formação do peróxido de hidrogênio, é necessário conhecer a distância em Volts que separa a reação de produção do peróxido de hidrogênio e a sua redução para água.

Para elucidar esta questão utilizou-se um eletrodo de disco rotatório de carbono vítreo numa solução $1 \mathrm{M}$ de $\mathrm{NaOH}$. $\mathrm{O}$ potencial foi varrido de 0,0 a $-1,5 \mathrm{~V}$ em relação a um referência de calomelano em $\mathrm{KCl}$ saturado, a uma velocidade de $5 \mathrm{mV} \mathrm{s}^{-1}$. Uma vez saturada a solução, o borbulhamento de oxigênio foi mantido durante as polarizações. A Figura 3-a mostra curvas de potencial-corrente para várias velocidades de rotação do eletrodo. É possível notar que todas as curvas exibem dois patamares bem definidos relativos às reações $\mathrm{O}_{2} \rightarrow \mathrm{H}_{2} \mathrm{O}_{2}$ e $\mathrm{H}_{2} \mathrm{O}_{2} \rightarrow \mathrm{H}_{2} \mathrm{O}$.

Observando-se as curvas da Figura 3-a fica clara a limitação do processo de redução pela velocidade de difusão do $\mathrm{O}_{2}$ na solução. $O$ aumento da velocidade de rotação, com a consequente redução na espessura da camada de difusão, melhora o transporte da espécie eletroativa para a superfície do eletrodo, aumentando a corrente limite. É possível notar que a corrente para a produção de peróxido de hidrogênio, na velocidade de rotação de $3600 \mathrm{rpm}$, é de $40 \mu \mathrm{A}$ no potencial de $0,6 \mathrm{~V}$ (primeiro patamar). Considerando que a área do eletrodo de disco de carbono vítreo é de $0,12 \mathrm{~cm}^{2}$, teremos uma densidade de corrente de $0,33 \mathrm{~mA} \mathrm{~cm}{ }^{-2}$, conforme previsto nos cálculos do ítem anterior. A Figura 3-b apresenta o gráfico de Levich para os dois processos. A organização dos dados nessa forma $\left(\mathrm{I}_{\mathrm{L}} v s \omega^{1 / 2}\right)$, é uma ferramenta importante para decidir quando um processo é limitado por transporte de massa. No caso dos resultados apresentados na Figura 3, ambos processos apresentam esta característica. A formação do peróxido de hidrogênio é controlada pela velocidade de difusão do oxigênio dissolvido e, a formação da água (segundo processo) é limitada pela difusão do $\mathrm{HO}_{2}{ }^{-}$eletrogerado e do $\mathrm{O}_{2}$ dissolvido. As correntes relativas ao segundo processo estão somadas às correntes limites para a formação do peróxido de hidrogênio e, com isso, a reta não passa pela origem. Porém isto não invalida o critério de Levich, onde a relação linear entre a corrente limite e $\omega^{1 / 2}$ certifica o controle por transporte de massa.

Outro fato importante, revelado pelos voltamogramas da Figura 3, é que a separação entre as duas etapas da reação de redução do oxigênio é de $400 \mathrm{mV}$, viabilizando a utilização deste substrato para a produção de peróxido de hidrogênio.

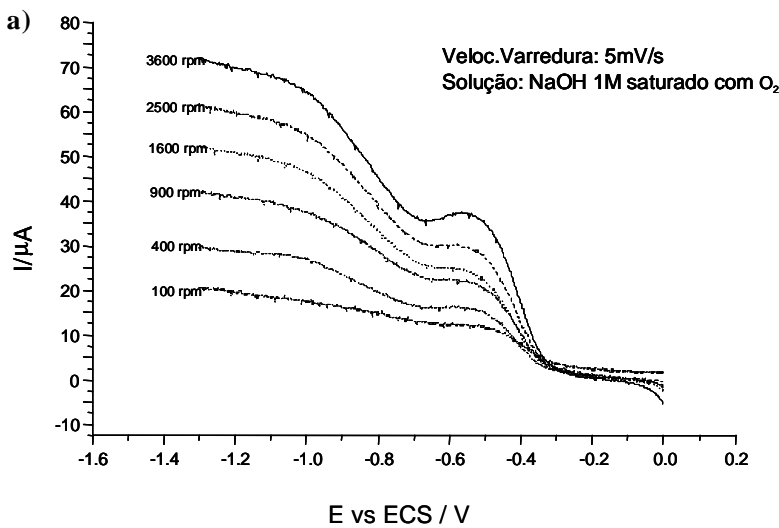

b)

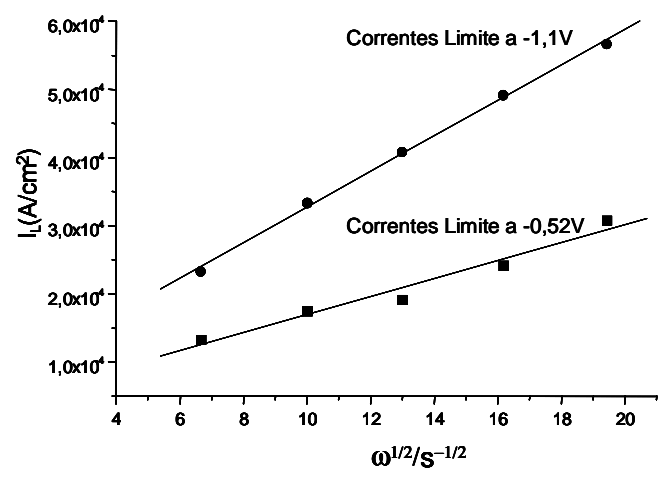

Figura 3. (a)Curvas potencial-corrente obtidas para a redução de oxigênio em eletrodo rotatório de carbono vítreo (A= 0,12 cm ${ }^{2}$ ). Demais condições descritas na figura. (b) Gráfico de Levich utilizando as correntes limite do primeiro e segundo processos. 


\section{Determinação do Coeficiente de Difusão do $\mathrm{O}_{2}$ dissolvido}

As correntes limite do primeiro processo da Figura 3-a, organizadas no gráfico de Levich (Figura 3-b) forneceram o coeficiente angular $(s)$, que está relacionado com o coeficiente de difusão do $\mathrm{O}_{2}$ para a superfície do catodo, da seguinte forma:

$$
\mathrm{s}=0,62 \mathrm{nFD}{ }^{0,67} v^{-0.17} \mathrm{C}_{\mathrm{SAT}}
$$

onde $\mathrm{n}$ é a viscosidade cinemática do eletrólito. Considerando a concentração de saturação da Figura $1 \mathrm{e} v=10^{-2} \mathrm{~cm}^{2} \mathrm{~s}^{-1} 19$, a equação (7) forneceu o valor de $8,5.10^{-7} \mathrm{~cm}^{2} \mathrm{~s}^{-1}$ para o coeficiente de difusão do oxigênio na solução $1 \mathrm{M}$ de $\mathrm{NaOH}$, a $23{ }^{\circ} \mathrm{C}$.

\section{Determinação do Coeficiente de Difusão do $\mathrm{HO}_{2}{ }^{-}$}

Se considerarmos que o equilíbrio nernstiano reversível prevalece para o par $\mathrm{HO}_{2}{ }^{-} / \mathrm{O}_{2}$ na superfície do eletrodo, então podemos escrever que ${ }^{19}$ :

$$
E_{1 / 2}=E^{0}+\frac{R T}{n F} \operatorname{In}\left(\frac{D_{R}}{D_{O}}\right)^{2 / 3}
$$

onde $\mathrm{E}_{1 / 2}$ é o potencial de meia-onda, $\mathrm{E}^{0}$, o potencial de equilíbrio reversível do par $\mathrm{HO}_{2}{ }^{-} / \mathrm{O}_{2}$ sobre o carbono vítreo e $\mathrm{D}_{\mathrm{R}} \mathrm{e}$ $\mathrm{D}_{\mathrm{O}}$, são os coeficientes de difusão das espécies reduzidas e oxidadas, respectivamente. De acordo com a equação (8), quando os coeficientes de difusão das espécies eletroativas são muito próximos, o potencial de meia-onda pode ser considerado como o potencial de equilíbrio reversível do par redox. Porém, este não parece ser o caso para o peróxido de hidrogênio. Para determinar o potencial do par redox foi utilizado o recurso de organizar os dados do primeiro processo da Figura 3-a num gráfico de $\ln \left[\mathrm{I} \cdot \mathrm{I}_{\mathrm{L}} /\left(\mathrm{I}-\mathrm{I}_{\mathrm{L}}\right)\right]$ vs $\mathrm{E}$, de forma a eliminar o efeito do transporte de massa dos dados cinéticos. Neste caso, o coeficiente angular das retas obtidas é o próprio coeficiente de Tafel. A Figura 4 mostra este gráfico onde, na ausência do efeito do transporte difusivo, todas as curvas, obtidas para as várias velocidades de rotação do eletrodo, apresentam extensos trechos lineares convergindo para o valor de potencial de equilíbrio de $\mathrm{E}^{0}=0,0 \mathrm{~V}$ vs ECS. Por outro lado, o potencial de meia-onda do primeiro processo, tomado da Figura 3-a, foi de $-0,41 \mathrm{~V}$ vs ECS. Substituindo todos os valores obtidos até o momento na equação (8), chegou-se ao valor de $5,4.10^{-6} \mathrm{~cm}^{2} \mathrm{~s}^{-1}$ para o coeficiente de difusão do peróxido de hidrogênio.

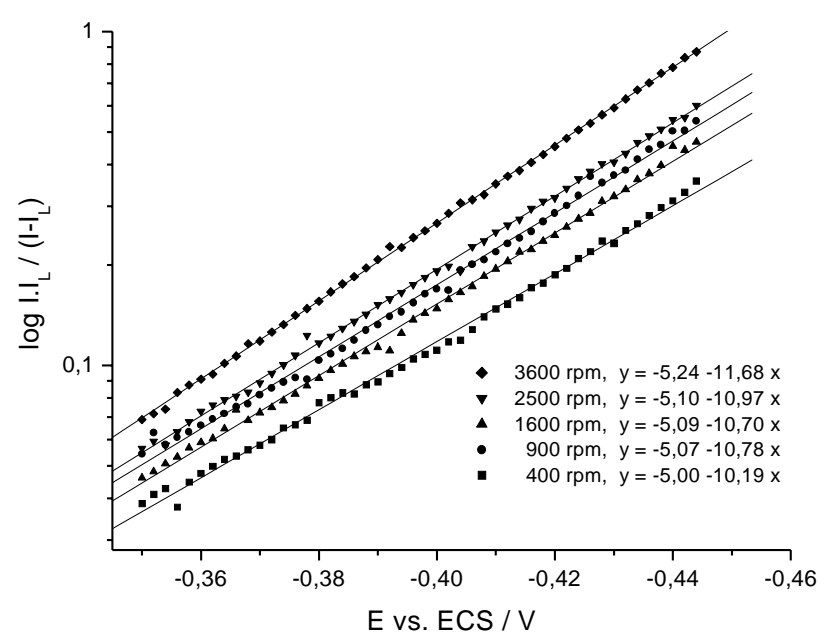

Figura 4. Gráfico de Tafel para as correntes de eletrogeração de peróxido de hidrogênio. Dados do primeiro processo da Figura 3-a.

\section{Estudo da Redução do Oxigênio sobre Carbono Vítreo Reticulado}

Quando se fala em eletrodos tridimensionais, o carbono vítreo reticulado (CVR) é sempre o candidato natural devido às suas qualidades descritas na literatura ${ }^{20}$. Uma esponja de carbono vítreo com 100 ppi pode conter uma área de até 66 $\mathrm{cm}^{2} \mathrm{~cm}^{-3}$. Isto faz com que a corrente limite obtida numa esponja de CVR possa ser duas ordens de grandeza maior do que em um eletrodo plano de mesma área geométrica.

Embora os resultados apresentados na Figura 3 tenham sido obtidos na superfície de um eletrodo de carbono vítreo monolítico, os eventos observados tendem a se reproduzir na superfície do carbono vítreo reticulado, com pequenas diferenças nos valores de potenciais. Isto pode ser consequiência do processo de síntese do material onde a resina furfurílica, após a carbonização, é vitrificada a $2000{ }^{\circ} \mathrm{C}^{21}$, minimizando as possíveis diferenças estruturais.

A Figura 5 mostra os voltamogramas obtidos sobre o eletrodo rotatório de CVR de $45 \mathrm{ppi}$, com área de $27 \mathrm{~cm}^{2}$. Embora os valores de corrente sobre o CVR sejam três ordens de grandeza maiores que aqueles obtidos sobre o disco de carbono vítreo monolítico, os patamares de corrente não estão bem definidos, como já foi observado em outros experimentos relatados na literatura ${ }^{14}$. Este efeito pode ser atribuído ao fato de que a penetração da corrente é limitada em eletrodos tridimensionais, devido à queda ôhmica em seu interior ${ }^{22}$. Além disso, a esponja de carbono, quando submetida ao movimento de rotação cria uma camada estagnante de eletrólito em seu interior. Estes fatos levam à relações potencial/corrente que evidenciam uma reação não totalmente controlada por transporte de massa. Porém, este modo de controle da reação tem participação significativa pois o aumento da velocidade de rotação leva a valores mais altos de corrente.

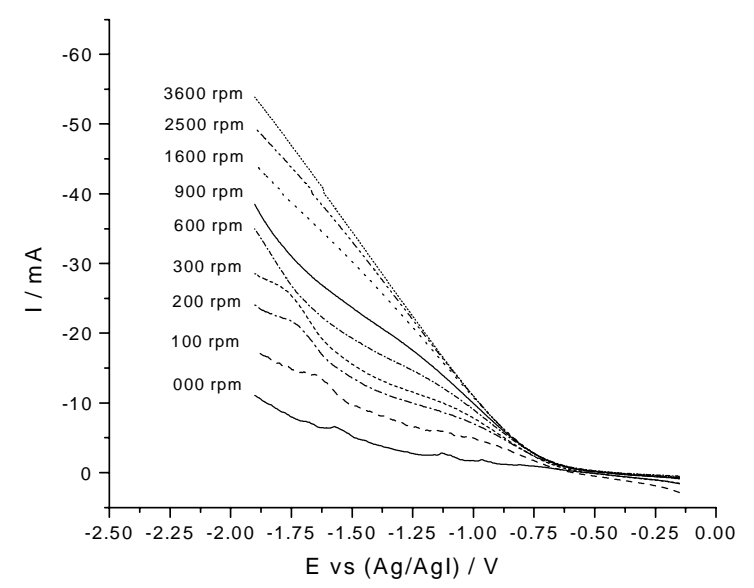

Figura 5. Curvas potencial-corrente obtidas para a redução de oxigênio em eletrodo rotatório de carbono vítreo reticulado de 45 ppi e área de $10 \mathrm{~cm}^{2}$. Velocidade de varredura de $5 \mathrm{mV} \mathrm{s}$.

Como se observa na Figura 5, é possível divisar o primeiro patamar, embora mal definido, entre $-1,1 \mathrm{~V}$ e $-1,5 \mathrm{~V}$ vs $\mathrm{Ag} /$ AgI (aproximadamente entre $-0,48 \mathrm{~V}$ e $-0,88 \mathrm{~V}$ vs ECS). Na Figura 3, o primeiro patamar está definido entre $-0,55 \mathrm{~V}$ e $0,65 \mathrm{~V}$ vs ECS. Portanto, sobre o CVR a geração de peróxido de hidrogênio começa em valores mais positivos e estende-se até valores mais negativos.

\section{Eletrogeração de Peróxido de Hidrogênio Sobre CVR a Potencial Constante}

O eletrodo da Figura 1 foi utilizado para a geração de peróxido de hidrogênio a potencial constante com valores de 
potenciais de $-1,1 \mathrm{~V},-1,3 \mathrm{~V},-1,6 \mathrm{~V}$ e $-1,7 \mathrm{~V}$ vs $\mathrm{Ag} / \mathrm{AgI}$, mantendo-se a concentração de saturação de $\mathrm{O}_{2}$ em solução. A velocidade de rotação usada foi de $200 \mathrm{rpm}$, apenas para manter a concentração de oxigênio homogeneizada. A Figura 6 mostra os perfis de concentração do peróxido de hidrogênio em função da carga aplicada, para os quatro valores de potenciais acima. É interessante observar que todas as curvas atingem um limite de concentração. Este valor constante de concentração, apesar da continuação do processo eletrolítico, pode ser atribuído a um equilíbrio entre a taxa de eletrogeração e a taxa de decomposição. É interessante observar que, à medida que o potencial aumenta de $-1,1 \mathrm{~V}$ até $-1,6 \mathrm{~V}$, obtém-se maiores velocidades de formação e maiores concentrações de equilíbrio. No entanto, no potencial de $-1,7 \mathrm{~V}$ a velocidade de formação e a concentração de equilíbrio são menores. Este último significa um sobrepotencial maior para a geração do peróxido mas, ao mesmo tempo, também para a geração da água. Este efeito já pode ser observado a partir do potencial de $-1,6 \mathrm{~V}$ quando a eficiência catódica começa a cair. A eficiência catódica é obtida pela razão entre a quantidade de carga utilizada para a produção de peróxido de hidrogênio e a carga total fornecida ao sistema durante um intervalo de tempo, podendo ser calculada pela expressão:

$\mathrm{EC}=\frac{100 \cdot \mathrm{n} \cdot \mathrm{F} \cdot \Delta \mathrm{m}}{\mathrm{M}_{\mathrm{i}} \cdot \mathrm{I} \cdot \Delta \mathrm{t}}$

onde $\Delta \mathrm{m}$ é a massa de peróxido de hidrogênio produzida (g), I a corrente elétrica aplicada ao sistema (A), $\mathrm{M}_{\mathrm{i}}$ a massa iônica da espécie envolvida ( $34 \mathrm{~g} \mathrm{~mol}^{-1}$, neste caso), $\Delta \mathrm{t}$ o tempo no qual a corrente é aplicada ao sistema (s) e EC a eficiência de corrente, em \%. A Tabela 2 mostra as eficiências catódicas para a formação do peróxido de hidrogênio que aumenta até $-1,3 \mathrm{~V}$ e começa a decrescer para os valores maiores de potencial.

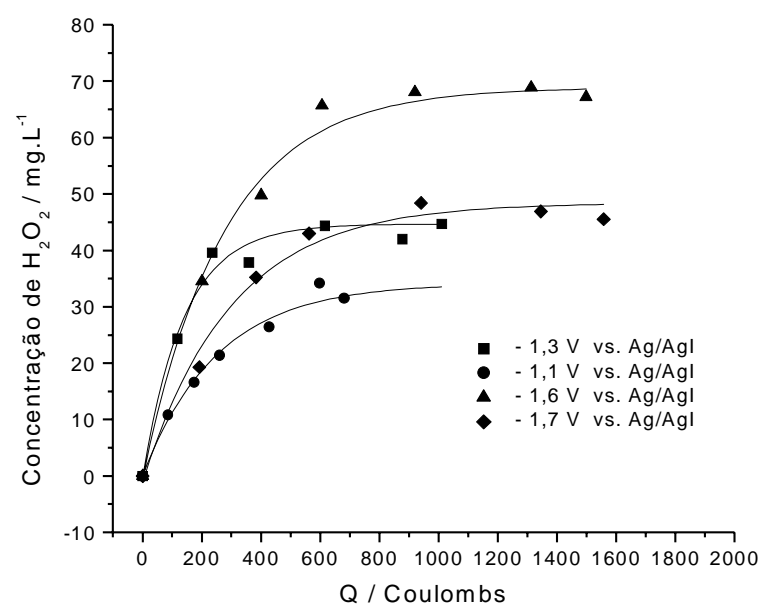

Figura 6. Perfis de concentração de peróxido de hidrogênio, eletrogerado sobre carbono vítreo reticulado de 20 ppi nos potenciais indicados, em função da carga aplicada.

Tabela 2. Eficiência catódica em função do potencial aplicado na eletrogeração de peróxido de hidrogênio sobre um catodo de CVR.

\begin{tabular}{cc}
\hline Potencial vs Ag/AgI/ & $\begin{array}{c}\text { Eficiência } \\
\text { Catódica/ \% }\end{array}$ \\
V & 23,4 \\
$-1,1$ & 29,6 \\
$-1,3$ & 27,7 \\
$-1,6$ & 19,1 \\
$-1,7$ & \\
\hline
\end{tabular}

\section{CONCLUSÕES}

O peróxido de hidrogênio pode ser eletrogerado in loco a partir de uma solução aquosa saturada com oxigênio. A solubilidade do oxigênio é baixa levando o processo de redução ao controle por transporte de massa com baixos valores de corrente limite. Para tornar viável a eletrossíntese deste importante oxidante é necessário a utilização de eletrodos tridimensionais. Neste sentido o carbono vítreo é um material adequado pois, além de ser encontrado na forma reticulada, separa os processos de produção da água e do peróxido de hidrogênio em $400 \mathrm{mV}$.

Os experimentos voltamétricos com eletrodo rotatório de carbono vítreo reticulado mostraram que os patamares de corrente limite não se definem muito bem e a seleção do potencial mais adequado para a eletrossíntese do peróxido de hidrogênio pode ser feita através do acompanhamento da eficiência catódica em experimentos a potencial constante.

\section{REFERÊNCIAS}

1. Dodson, M.; Tappi J. 1990, 73, 82.

2. Shearman, J.; Chem. Eng. 1992, 99, 55.

3. Wilson, S.; Chem. Ind. 1994, April, 255.

4. Reich, M. S.; Chem. \& Eng. News 1995, January $30,15$.

5. Do, J-S.; Chen, C-P; J. Electrochem. Soc. 1993, 140, 1632.

6. Do, J-S.; Chen, C-P; J. Appl. Electrochem. 1994, 24, 936.

7. Ponce de Leon, C.; Pletcher, D.; J. Appl. Electrochem. 1995, 25, 307.

8. Di Iglia, R.; Rodrigues, C. A.; Bertazzoli, R.; XI Simpósio Brasileiro de Eletroquímica e Eletroanalítica, Maragogi, AL, 1999.

9. Brillas, E.; Bastida, R. M.; Llosa, E.; Casado, J.; J. Electrochem. Soc. 1995, 142, 1733.

10. Brillas, E.; Mur, E.; Casado, J.; J. Electrochem. Soc. 1996, 143, L49.

11. Brillas, E.; Sauleda, R.; Casado, J.; J. Electrochem. Soc. 1997, 144, 2374.

12. Alvarez-Gallegos, A.; Pletcher, D.; Electrochim. Acta 1998, 44, 853.

13. Alvarez-Gallegos, A.; Pletcher, D.; Electrochim. Acta 1999, 44, 2483.

14. Oloman, C.; Electrochemical Processing for the Pulp and Paper Industry, The Electrochemical Consultancy, Romsey (UK), 1996.

15. Gyonge, E.; Oloman, C.; $195^{\text {th }}$ Meeting of the Electrochemical Society, Seattle, May 2-6, 1999; Abstract 886.

16. Kirk-Othmer; Encyclopedia of Chemical Technologies, $3^{\text {rd }}$ Edition 1981, vol 13.

17. Catálogos Comerciais: Chemellec Cell- BEWT(Water Engineering)Ltd., England; EnviroCell- Deutsche Carbone, Germany; Retec Cell, EES Corporation, USA; FM Cell, Electrosynthesis, USA.

18. Bockris, J. O'M; Srinivasan, S.; Fuel Cells: their electrochemistry; Mc Graw-Hills; New York, 1969; p 437.

19. Bard, A. J.; Faulkner, L. R.; Electrochemical Methods: Fundamentals and Applications; Wiley; New York, 1980; p 283.

20. Wang, J.; Electrochim. Acta 1981, 261, 721.

21. Ferrari, P. E.; Rezende, M. C.; Widner, R.; Di Iglia, R.; Sousa, M. F. B.; Bertazzoli, R.; $50^{\circ}$ Congresso Anual da Associação Brasileira de Metalurgia e Materiais, São Pedro, SP, 1995.

22. Lanza, M. R. V.; Bertazzoli, R.; J. Appl. Electrochem. 2000, 30,61 . 